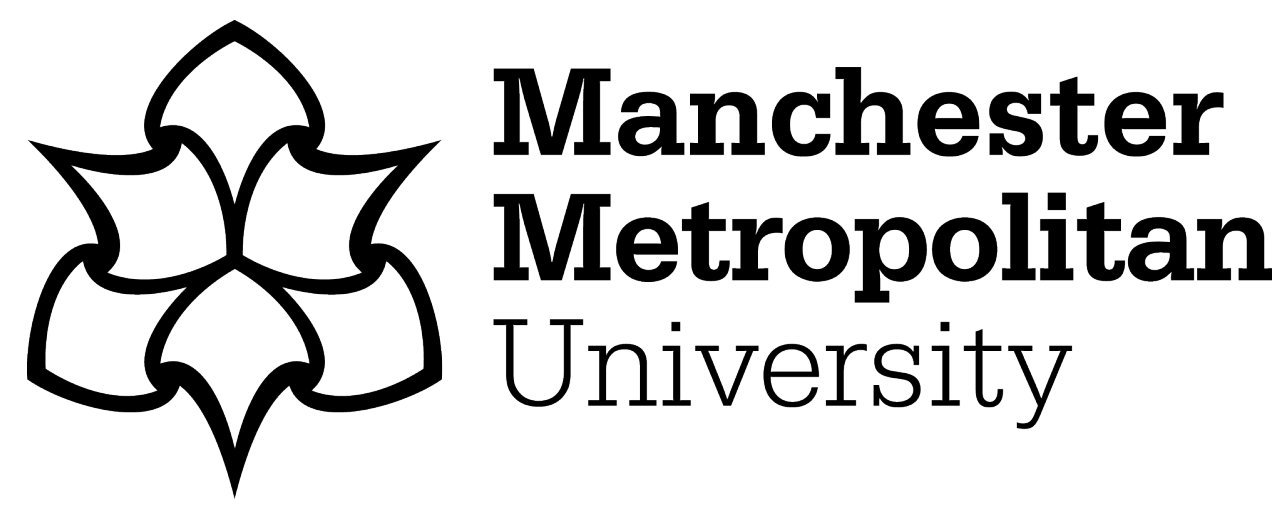

Reid, D, Rebbeck, T and McCarthy, C (2017) Clinical reasoning for complex cervical spine conditions. International Journal of Osteopathic Medicine, 27. pp. 45-51. ISSN 1746-0689

Downloaded from: https://e-space.mmu.ac.uk/619278/

Version: Accepted Version

Publisher: Elsevier

DOI: https://doi.org/10.1016/j.ijosm.2017.09.002

Usage rights: Creative Commons: Attribution-Noncommercial-No Derivative Works 4.0

Please cite the published version 


\section{Accepted Manuscript}

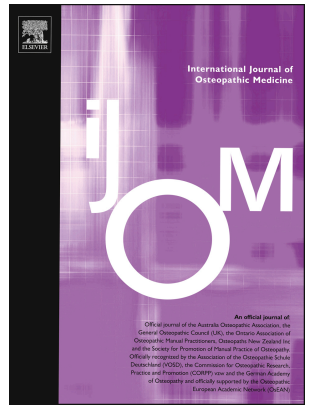

PII:

S1746-0689(17)30063-9

DOI: $\quad$ 10.1016/j.jjosm.2017.09.002

Reference: $\quad$ IJOSM 447

To appear in: International Journal of Osteopathic Medicine

Received Date: 1 April 2017

Revised Date: 28 August 2017

Accepted Date: 4 September 2017

Please cite this article as: Reid D, Rebbeck T, McCarthy C, Clinical reasoning for complex cervical spine conditions, International Journal of Osteopathic Medicine (2017), doi: 10.1016/j.ijosm.2017.09.002.

This is a PDF file of an unedited manuscript that has been accepted for publication. As a service to our customers we are providing this early version of the manuscript. The manuscript will undergo copyediting, typesetting, and review of the resulting proof before it is published in its final form. Please note that during the production process errors may be discovered which could affect the content, and all legal disclaimers that apply to the journal pertain. 
Clinical reasoning for complex cervical spine conditions

Authors:

Duncan Reid DHSc, FNZCP MHSc, PGDip (Manip Physio) Dip PT, BSc School of Clinical Sciences, Auckland University of Technology

Private Bag 92006 Auckland 1142

New Zealand

Ph: +649219999 ext 7806

Email: duncan.reid@aut.ac.nz

Trudy Rebbeck PhD FACP MAppSc(ManipPHty) BAppSc(Phty)

Specialist Musculoskeletal Physiotherapist ; NHMRC Research Fellow University of Sydney

Australia

Christopher McCarthy PhD, FCSP, FMACP Clinical Fellow, Manchester Movement Unit

Manchester School of Physiotherapy Brooks Building

Manchester Metropolitan University

United Kingdom

Key Words

Clinical reasoning, case study, vertebral artery dissection, tempero mandibular joint, whiplash 


\title{
Clinical reasoning for complex cervical spine conditions
}

\begin{abstract}
Clinical reasoning is at the cornerstone of clinical practice. Case studies are not viewed as highly in the evidence hierarchy as randomised controlled trials but they provide valuable insights into individual cases and clinicians often relate well to these as there are parallels with patients they see in their own clinics. This master class presents three cases related to cervical spine pathologies as assessed or managed by three physiotherapists. These therapist are experienced clinicians and academics and bring their expertise of both worlds (clinical and academic) to these cases providing an overview of the case, followed by their interpretation and rationale for care with their clinical reasoning insights. The cases where originally presented at a recent international physiotherapy conference and reworked for journal publication.
\end{abstract}

\section{Introduction}

The International Federation of Orthopaedic Manipulative Physiotherapists (IFOMPT) is a world-wide group of physio/physical therapists whose mission is to promote international excellence and unity in clinical and academic standards for manual and manipulative physiotherapists. Every four years a major international conference is held by IFOMPT to bring together clinicians and academics to listen and debate the latest trends in manual and manipulative therapy. The most recent conference was held in Glasgow in July 2016. At these conferences a number of high quality randomised controlled trials were presented as well as focussed symposia from world leading experts. These symposia are often interactive and allow the clinicians to question and debate with the presenters. One of the many popular symposia was titled Clinical Reasoning for the Cervical Spine led by $\mathrm{X}$ and 
contributed to by $\mathrm{X}$ and $\mathrm{X}$ These three presenters are both practicing clinicians and academics. The aim of the symposia was to present three cases related to cervical spine conditions, one a whiplash related disorder, one a cervical spine/temporomandibular joint dysfunction and one a cervical spine/ cervical artery disorder. The key features of each case were presented then the interpretation and clinical reasoning involved in the management. The presenters then invited the audience to consider the clinical reasoning process and the lessons to be learnt. Whilst case studies are not considered high quality evidence ${ }^{1}$ they often resonate with clinicians as they reflect the day to day challenges of clinical practice rather than the summated results of RCT's. The purpose of this master class is to provide a summary of the three cases presented in the symposia.

\section{Case 1 Case of a patient who suffers a vertebral artery dissection}

This is a case of a patient who was subject to a medical review but not treated by Dr Reid but one he will provide commentary for. The patients name and some details of the case have been removed or altered to preserve anonymity. A male patient in his mid-sixties presented to a physiotherapy clinic with a right sided neck pain and headache. The pain in the neck is described as dull ache, rated $3 / 10$ on the Numerical Pain Rating Scale (NPRS) and he feels the pain is constant in nature. The neck pain radiates to the right side of the head. He has had this for a few days and felt the pain in his neck after rolling over in bed, the headache followed. Aggravating features: The pain is worse with turning the head to the right, sleeping and driving especially turning right (see Figure 1). Easing features: The neck pain was better with heat and simple analgesics such as Panadol.

Associated features: The patient complained that the right eye was watering and closing, and there was a feeling of gland in the side of the neck that was cold and swollen. There 
were no complaints of dizziness, or double vision, or symptoms asked for in Vertebral Artery Insufficiency (VBI) screen.

Medical history: The patient had known high blood pressure, high cholesterol, and was previously a long term smoker.

On examination the treating physiotherapist found active range of motion loss with pain aggravated with right rotation. Reduced range of motion passively in the $\mathrm{C} 01$ and $\mathrm{C} 1 / 2$ joints on the right. No VBI type symptoms provoked with rotational testing. The provisional diagnosis was upper cervical joint dysfunction with cervicogenic headache.

The treatment consisted of unilateral mobilisation to upper cervical spine in supine. Grade 3-4 level of intensity was applied. No high velocity thrust techniques were performed. Initially there was some improvement in range and a decrease in headache intensity. A similar treatment approach was continued for the next four visits. The outcome of these interventions was-a fluctuating change in headache and neck pain but the symptoms never really resolved. The watery eye and neck lump symptoms did not change at any time during the course of the treatment.

The night after the $5^{\text {th }}$ treatment the patient had diarrhoea and vomiting and reported difficulty swallowing from 3 am onwards. He was admitted to hospital with right beating nystagmus, double vision worse on the gaze to the right, left partial ptosis, mild facial weakness, pooling of saliva in the mouth, dysmetria of the left arm and possibly leg and decreased sensation of the left upper limb. His blood pressure was 176/94 and pulse regular. The CT angiogram of the neck revealed damage to left vertebral artery lumen consistent with a left vertebral artery dissection (VAD). 
Insert figure 1 here
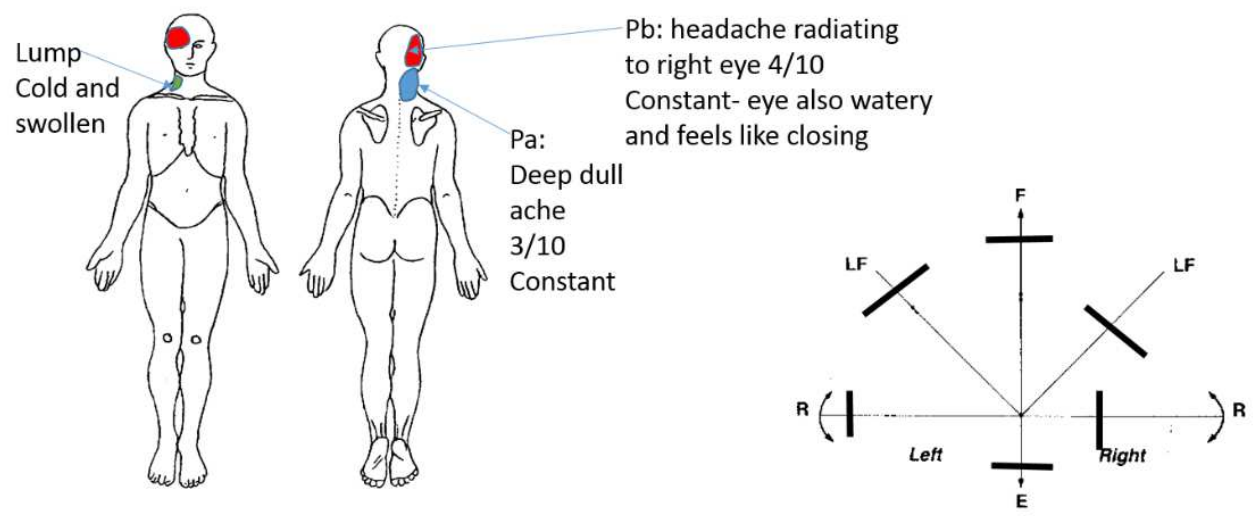

Figure 1 Body chart and active range of motion tests, range limited by pain

\section{Interpretation}

The purpose of this master class is not to determine if there is a cause and effect relationship between the physiotherapy treatment and the VAD but to use this case to look at the presenting features and whether or not evidence and clinical reasoning may have been able to pick up some of the key features of this case sooner.

Data from the United States suggests the average annual incidence for cervical artery dysfunction (CeAD) is 2.6 persons per 100000 population ( $95 \% \mathrm{Cl} 0.9$ to $4.2^{2,3}$. Haneline and Lewokvich ${ }^{4}$ report that the majority of CeAD are spontaneous (61\%), 30\% are associated with trivial trauma, and approximately $9 \%$ associated with cervical spine manipulation. The ability to get the true incidence of CeAD in relation to cervical spine manual and manipulative therapy has proven a challenge as there are no prospective epidemiological 
studies to support the true incidence. Based on retrospective studies the incidence rates range form $1: 630,00^{5}$ to $1: 5,000,000^{6}$.

The guidelines for the pre manipulative testing and management of cervical spine conditions were formalised in the physiotherapy profession by Magery et $\mathrm{al}^{7}$ in 2004 . This screening should involve a detailed history, followed by a physical examination that included the assessment of cervical rotation and ligament stability testing. The subjective examination placed an emphasis on asking for symptoms that might indicate vertebrobasilar artery insufficiency (VBI), which included: dizziness, double vision, dysarthria, dysphagia, drop attacks, numbness of the face and tongue and nausea (5D's and 3 N's). During the physical examination the minimum testing recommended included: Sustained end range cervical rotation to the left and right or the position or movement which provoked symptoms as described by the patient. All positions should be sustained for a minimum of 10 seconds, unless symptoms were provoked sooner. The guidelines recommend that the therapist should examine the patient's eyes for the production of nystagmus while the head is held in the sustained position and simultaneously question the patient about the reproduction of symptoms.

Whilst the above had been the accepted standard of practice, a number of key issues have emerged in more recent research: The actual physical tests of cervical rotation have limited diagnostic utility for the reproduction of the VBI symptoms (sensitivity of $0 \%-21 \%$ and specificity of $23 \%-90 \%)^{8}$. The importance of the subjective history in particular health related risk factors now has greater importance in predicting risk than the physical tests ${ }^{9}$.The physical tests need to include an assessment of blood pressure and potentially the cranial nerves. $^{9}$ 
A recent paper by Vaughan et al ${ }^{10}$ has also summarised the key risk factors associated with manual therapy and cervical artery dysfunction. These included, relevant to this case: acute onset unilateral cervical spine pain, acute onset occipital, frontal, supraorbital or temporal headache, a history of cervical spine trauma (including minor or 'trivial' trauma), and a history of hypertension and risk factors for cardiovascular disease.

The updated guidelines from Rushton et al ${ }^{9}$ also recommend taking the patients' blood pressure. Hypertension is considered a risk factor for carotid and vertebral artery disease. More acutely, an increase in blood pressure may be related to acute arterial trauma, including of the internal carotid and vertebral arteries ${ }^{11}$. Assessing for cranial nerve dysfunction may also be useful. Examination of the peripheral nerves, cranial nerves, and for an Upper Motor Neurone lesion will assist in evaluating the potential for neurovascular conditions $^{12}$.

With all this information available reflecting on the case above offers the following observations. Had the therapist taken a greater interest in the medical history looking the key risk factors related to vascular health, taken the patients' blood pressure and perhaps tested the cranial nerves, then therapist may have referred the patient back to the medical profession for further investigations. The lack of response and change in the symptoms with the manual therapy interventions would also have warranted a review. The ability to clinicians to keep up with the latest guidelines is always a challenge but presenting cases like this is a helpful part of that translation. 


\section{Case 2 Case of a patient with TMJ and cervical dysfunction}

\section{Introduction}

This case study considers the relationships between the Temporo-mandibular (TMJ) region and cranio-cervical junction (CCJ). The regions are anatomically, biomechanically and neurologically interconnected and the clinical take home message of this case study is that an integrated examination of both areas is appropriate in cases of cranio-facial pain.

\section{Case Presentation}

The subject of this case study was a 46-year-old man with right TMJ and mandibular ramus pain on mouth opening, particularly when his upper cervical spine was positioned in flexion and right rotation (the position adopted to cradle a telephone handset under the chin). When doing this he would also experience right-sided occipital headache. The pain had developed a week after he had bumped his forehead whilst going through a low-lintel doorway, six months previously. He had seen his Dentist who had suggested the mandibular pain might be associated with a posteriorly "displaced disc" and had three sessions of TMJ mobilisation (performed in cervical neutral) with only hours of pain relief after each session.

On interview and examination the patient had some underlying anxiety regarding the possibility of the TMJ "slipped disc" but no signs of central sensitivity or sympathetic nervous system dysfunction. Cranial nerve examination was normal. The patient had a narrow jaw but no facial asymmetries. Motion assessment, of the TMJ, revealed no active or passive movement abnormalities or clicking when performed in cervical spine neutral 
however there was local tenderness on the posterior aspect of the mandibular ramus, at the level of the external auditory meatus. When maximal mouth opening was examined, with the upper cervical spine placed in a flexed and ipsilaterally rotated position, there was pain both in the right $\mathrm{CCJ}$ and mandibular regions.

On examination of the active movements of the $\mathrm{CCJ}$ there was reduced active movement into flexion and right rotation, by $25 \%$. Passive anterior-posterior accessory glides, undertaken with the $\mathrm{CCJ}$ in flexion, right rotation, reproduced the mandibular and CCJ pain with and anterior glide of C1. The movement was restricted and painful early in passive range. The patient found it impossible to recruit his deep neck flexors ${ }^{13}$, particularly on the right and had poor smooth-pursuit neck torsion test ${ }^{14}$.

Pain in the right $\mathrm{C} 1$ pre-vertebral space can be due to sensitivity of numerous tissues including, the upper cervical sympathetic ganglion, the pre-vertebral fascia, the alar fascia, the anterior capsules of the C0/1 zygapophyseal joint, accessory atlanto-axial ligament, lateral atlanto-occipital ligament, rectus capitis anterior, rectus capitis lateralis, longus capitus, superficial / deep temporal arteries / veins, internal maxillary artery, facial nerve and skin. Thus, in this $2 \mathrm{~cm}^{2}$ space, palpation alone made identifying the source of pain impossible. The combination of $\mathrm{CCJ}$ flexion (normal range $25^{\circ}$ ), and ipsilateral rotation (normal range $4-6^{0}$ ) will position the atlas relatively anteriorly on the occipital condyles ${ }^{15}$ and thus with the posterior movement of the mandible, during end of range mouth opening, it is possible that there was some compression of sensitive structures. There is also 
evidence that contraction of mandibular muscles and tongue influences activity in the muscles, and range of movement of the $\mathrm{CCJ}^{16,17}$.

Insert figure 2 here

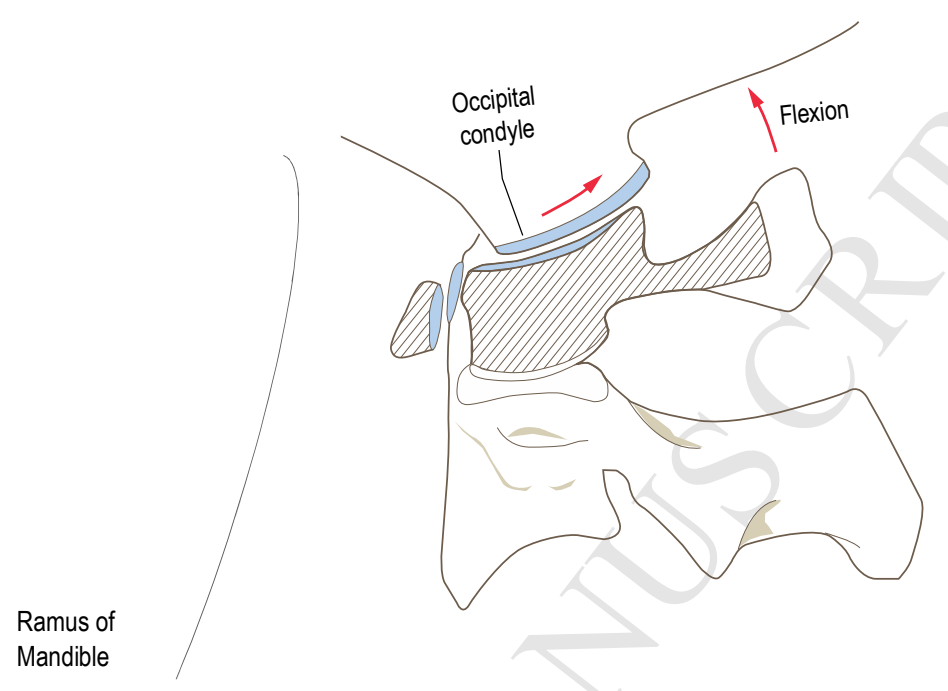

Figure 2: Relatively anterior $\mathrm{C} 1$ on $\mathrm{CO}$ during flexion, ipsilateral rotation and proximity of the mandible.

\section{Management Approach}

One manual therapy approach, advocated to address direction specific spinal pain, is combined movement theory ${ }^{18,19}$. When a direction specific combination of movements results in severe pain the approach advocates positioning the region in a diametrically opposite position and inducing an afferent stimulus to evoke brain-orchestrated descending pain inhibitory mechanisms. Passive mobilisation has been shown to selectively reduce perception of pain ${ }^{20,21}$. 
The initial treatment selected involved positioning the patient's CCJ in extension, left rotation with the mouth closed. In this position passive, oscillatory $(2 \mathrm{~Hz})$ accessory (anterior to posterior) gliding of $\mathrm{C} 1$ on the $\mathrm{CO}$ resulted in a progressive reduction in $\mathrm{CCJ}$ pain, during treatment, and after treatment a significant reduction in pain on mouth opening (when in flexion / right rotation). This was repeated twice, with complete ablation of pain. Following this the patient could recruit their deep neck flexors and the smooth pursuit neck torsion test had normalised.

\section{Interpretation}

The rapid reduction in symptoms, evoked with treatment of the $\mathrm{CCJ}$, provided a positive message to address the patient's anxiety regarding the possible TMJ "slipped disc". The dramatic improvement was explained to the patient in terms of the neurophysiological response evoked and a home stretch was prescribed mimicking the manual therapy provided in the session. This was to reinforce the message that the patient had active control of the impairment and that with their own stretching regime they could desensitise the problem without the need of professional help. A deep neck flexor strengthening and sensorimotor control programme was also prescribed to address specific control impairments that can remain unless specifically addressed ${ }^{22}$.

The mechanisms underlying the ablation of pain can be considered from biomechanical, neurophysiological and psychological perspectives. Biomechanically, the anterior-posterior glide of C1 on C0 could, theoretically, have pushed the atlas posteriorly and reduced 
compression on the sensitised anterior vertebral tissues, although the concept of positional vertebral dysfunction has not been shown to be a valid proposition ${ }^{23}$. In addition, there is no evidence for manual therapy "readjusting mal-positioned vertebrae" ${ }^{23}$ thus this theory is scientifically unacceptable. From a neurophysiological perspective rapid reductions in pain have been observed following passive mobilisation techniques and there are strong links between ablation of pain and improvement in range of motion and return to normal motor function ${ }^{22}$. There are well established connections between $\mathrm{CCJ}$ and face, via the trigemino-cervico nucleus, likely to explain how afferent stimulus of one region reduces pain in another ${ }^{24}$. However despite our inability to precisely understand how upper cervical passive movement can lead to resolution of a painful impairment, in both neck and TMJ, the necessity to consider the positioning of the CCJ whilst examining the TMJ, in patients with cranio-facial pain, is a valuable clinical message. 
Case 3 A female 3 years post whiplash, with high risk factors for non-recovery including widespread cold hyperalgesia, responds to musculoskeletal physiotherapy. Why?

\section{Introduction}

At least $50 \%$ of people with whiplash associated disorders $(W A D)^{25}$ do not recover in 3 months and transition to chronicity. Best management for people with chronic whiplash is under debate, given our recent high quality randomised trial found equivocal effects for one session of advice vs a comprehensive exercise programme ${ }^{26}$. This has led to discussion as to whether exercise should be considered at all for the management of chronic whiplash.

Clinical reasoning would suggest that there are patients who respond to a physiotherapy-led exercise approach. Background prognostic work suggests that individuals with WAD who are less likely to respond to physiotherapy- led exercise approaches are those with abnormal pain processing (eg widespread cold hyperalgesia) and high-level of psychological distress. ${ }^{27-29}$ However, in many trials of chronic whiplash to date, responders have been unable to be identified. ${ }^{30,31,26}$ Given this, qualitative studies such as this case study may provide insight as to where potential responders to physiotherapy led-exercise may lie.

\section{Clinical presentation}

A 31 year old female health care professional and elite rower presented to a specialist musculoskeletal physiotherapist in Australia. She was involved in a motor vehicle accident 3 years previously, whilst on a work holiday in Europe. Initial diagnostic work up excluded fracture and she was discharged. Initial symptoms included neck pain, headache, left sided arm parasthesia and left sided leg pain. Physiotherapy treatment in Europe included manual 
therapy and acupuncture, which if applied too vigorously would aggravate symptoms. Upon return to Australia she presented to a specialist musculoskeletal physiotherapists around 3 years post injury.

Presenting symptoms are outlined in Figure 3, and included moderate neck pain and headache. Symptoms were aggravated by activities that involved an outstretched hand (eg on the ergo rower) and when driving. Functional limitations also included her ability to lift weights at the gym and rowing on the water. These were quantitatively assessed using the patient specific functional scale as $2 / 10$, and $0 / 10$ respectively. The Neck Disability Index score was $18 / 50$ indicating moderate self-reported disability due to neck pain. The pain catastrophising scale ${ }^{32}(17 / 52)$ was unremarkable, however the impact of events scale was $69 / 75$ indicating severe risk of post-traumatic stress symptoms. She otherwise had no significant prior history and was medically well.

The physical examination revealed normal cervical ROM for her age (Table 1), apart from reduced and painful cervical extension. An upper limb neurological examination revealed normal responses to power and myotomal strength testing as well as normal responses to deep tendon reflexes. There was mild provocation of arm pain during palpation of the $C 5,6$ segment anteriorly and provocation of the headache with palpation of the C1 posterior arch. The OC1 segment was considered hypomobile during passive physiological intervertebral movement testing, and the flexion rotation test ${ }^{33,34}$ was negative.

Formal testing of the scapula and cervical muscle performance revealed impairments associated with her symptoms. Observation of the scapula posture revealed a downward sloping scapula indicating overuse of the levator scapulae at rest. Electromyographic testing using surface electrodes placed on the skin over the levator scapulae and upper trapezius 
region revealed activity levels of $>50 \mu \mathrm{V}$ during simulated typing at $>90 \mu \mathrm{V}$ during simulated rowing. This activity reduced to $<20 \mu \mathrm{V}$ after several repetitions of an exercise designed to relax the levator scapulae ${ }^{35}$ and importantly the resting cervical pain and headache together with cervical extension range improved after this test exercise. The scapula holding test ${ }^{36}$ performed prone revealed her ability to hold the correct pattern for 5 seconds before substituting with upper trapezius and rhomboids to hold the position. The cranio-cervical flexion test ${ }^{37}$ indicated increased activity of the left sided SCM at $22 \mathrm{mmHg}$ after one repetition. The cervical extensor test ${ }^{38}$ revealed fatigue after 3 repetitions.

Testing for neural sensitivity revealed reproduction of the left arm symptoms with an upper limb tension test. Similarly testing for mechano-sensitivity of the $C 2$ nerve was positive, with craniocervical flexion reduced and headache provoked when performed with the addition of a straight leg raise. Pressure pain thresholds (PPT) and cold pain thresholds (CPT) were reduced at both local and remote sites (Table 2).

Insert figure 3 here and tables 1 and 2 


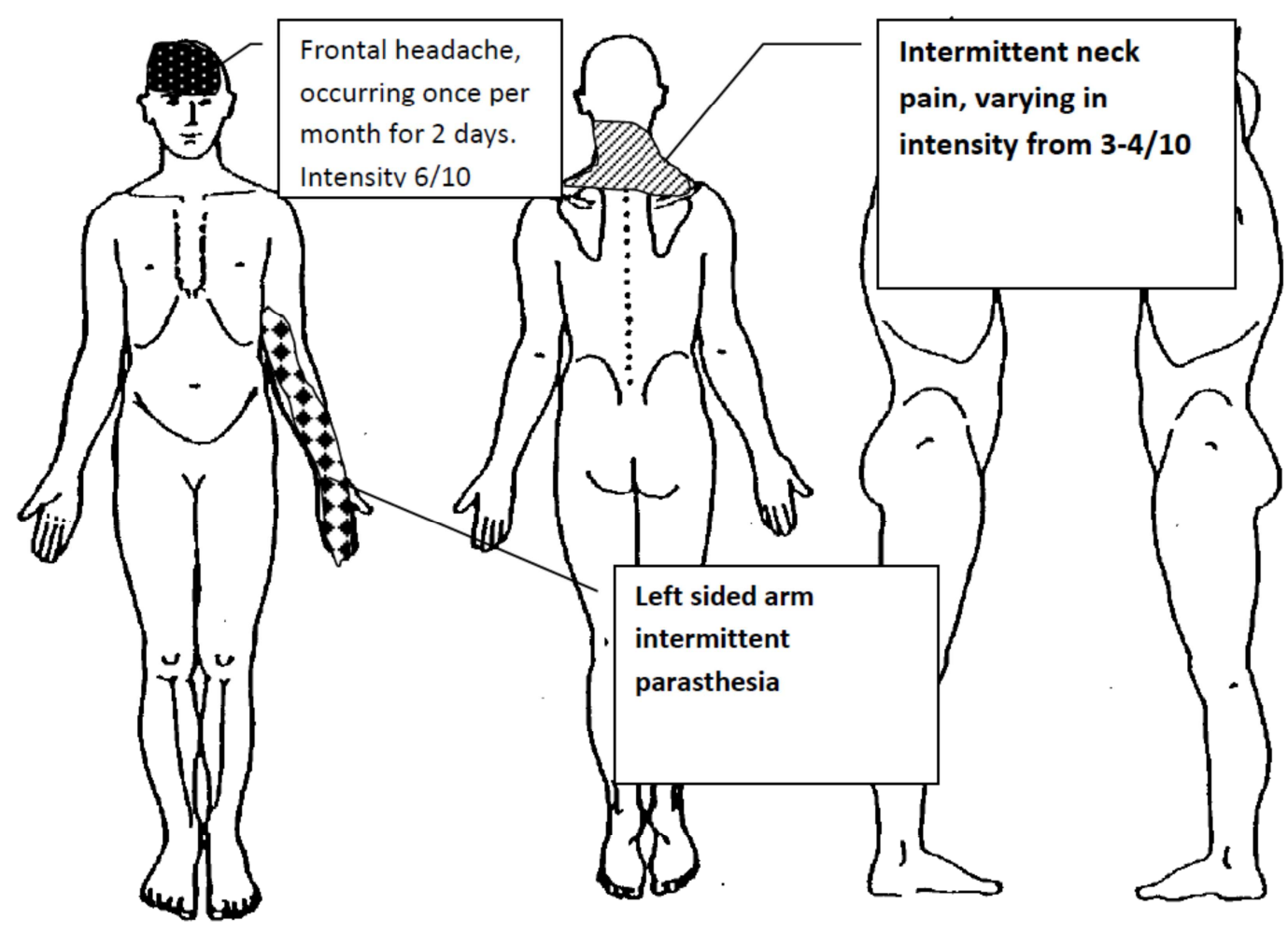

Table 1: Cervical range of motion (measured by inclinometer) and symptom response

\begin{tabular}{|c|c|c|}
\hline Movement & Range & Symptom response \\
\hline Flexion & 55 degrees & Increase in tightness in neck and head \\
\hline Extension & 40 degrees & Increased neck symptoms \\
\hline Right rotation & 70 degrees & No change in symptoms \\
\hline Left rotation & 70 degrees & No change in symptoms \\
\hline
\end{tabular}


Table 2: Cold and pressure pain thresholds at baseline

\begin{tabular}{|lll|}
\hline Site & $\mathrm{CPT}^{\circ} \mathrm{C}$ & PPT (kPa \\
\hline Neck Left C2 & $\mathbf{2 5 . 9 7}$ & $\mathbf{1 0 6 . 6 7}$ \\
\hline Left Upper Trapezius & $\mathbf{2 6 . 2 7}$ & $\mathbf{1 4 9 . 6 7}$ \\
\hline Left Wrist & $\mathbf{2 4 . 7}$ & $\mathbf{1 5 5 . 3 3}$ \\
\hline Tibialis Anterior & $\mathbf{2 4 . 0 3}$ & $\mathbf{2 1 5 . 6 7}$ \\
\hline $\begin{array}{l}\text { CPT Measured by a thermal sensory testing system (MSA } \\
\text { Sweden). }\end{array}$ & \\
Pressure Pain Thresholds (PPT): measured & \\
probe size of $1 \mathrm{~cm}^{2}$ (Somedic AB Sweden) applied at a hater, Somedic, \\
\hline
\end{tabular}

\section{Investigations}

The report accompanying the cervical MRI revealed a central C5,6 disc protrusion without cord compression or interformainal encroachment. Neurophysiological examinations assessing conduction speed of the ulnar, median and radial nerves were essentially normal.

\section{Diagnosis}

The patient's presenting symptoms were consistent with a triage diagnosis of WADII. There was no evidence of WADIII given the MRI, neurophysiological test findings and normal clinical testing for radiculopathy. There was evidence of widespread abnormal sensory processing given the lowered PPT's and CPT's at local and remote sites. Associated motor impairments appeared to be poor scapula control, craniocervical flexion and cervical extensor control. Post-traumatic stress symptoms were present given the high score on the IES. These factors together would sub-classify the patient with WADIIc ${ }^{39}$ given the associated psychological distress and emergent evidence of central sensitization. 


\section{Management and Outcome}

The patient was managed a total of 6 times over 4 months. Management included rehabilitation of the impairments inducing improving scapula control, craniocervical flexion control and cervical extensor endurance. Exercises were progressed at each session to become more loaded and increasingly functional (eg progressing from maintaining appropriate scapula control in simulated typing to simulated then actual rowing). She was referred to a psychologist for management of post-traumatic stress. At around 4 months she was referred to a specialist sport physiotherapist to advice on high level training to enable return to elite rowing. At four months post initial presentation, the symptoms had considerably reduced (neck pain 1/10) and resolution of arm paraesthesia. The neck disability index had reduced to $4 / 50$ and the patient reported overall recovery at $4 / 5$ on a Likert scale of global perceived recovery (range -5 vastly worse to +5 completely recovered). She had returned to training at the gym at 70\% (PSFS 7/10) of her previous capacity and rowing on the water at 70\% (Patient Specific Functional Scale (PSFS) 7/10) of her prior capacity. After further training with the sports physiotherapist she competed in her first elite rowing event successfully without provocation of symptoms.

\section{Discussion}

This case study illustrates an individual with chronic whiplash who responded well to a combined approach of specific and general exercise. She had several indicators at initial presentation would indicate she would not respond, including cold hyperalgesia and high scores on the impact of events scale (IES), indicating risk of post- traumatic stress disorder. Two potential sub-grouping approaches that may explain her response are a treatmentbased sub-grouping approach and a risk- based sub-grouping approach. 
An approach to sub-grouping based on clinical reasoning may assist in identifying responders. This case suggests that those whose symptoms respond to alteration of the motor system immediately using exercise, are more likely to respond to an exercise based approach. Background research underpinning the rationale for this is that impairment of scapula control, craniocervical flexion control and cervical extensor control are different in patients with whiplash compared with their age matched controls. ${ }^{39-42}$ Furthermore when rehabilitated, reduction in pain and disability occur ${ }^{44,45}$. In our $\mathrm{RCT}^{26}$, we were unable to identify responders to this exercise based approach. However data that were used to identify this were not based on clinical demonstration that changing motor performance using exercise changes pain. Rather, factors used were those determined apriori to predict non- recovery such as cold hyperalgesia or post-traumatic stress symptoms. These factors have strong evidence to predict non-recovery according to previous prognostic research (eg ${ }^{46,47}$ and clinical guidelines ${ }^{48,49}$, however do not consider clinical responsiveness. This case study suggests using immediate clinical responsiveness to the intervention to justify proceeding with such an approach should be considered. Increasingly we are cautioned by advocates for clinical reasoning ${ }^{50,51}$ not to blindly implement the evidence, rather to integrate clinical reasoning with current best practice.

A second sub-grouping approach that may explain the observed effect is a risk-based approach. Extrapolating Ritchie et als ${ }^{50,51}$ clinical prediction rule for acute WAD to this presentation, she would have been at moderate to high risk of not recovering at baseline. Patients at moderate risk of non-recovery at baseline have scores of $>32 \%$ on the NDI and $>3$ on the arousal subscale of the post-traumatic stress scale, whilst those at high risk have scores of $>40 \%$ on the NDI and $>6$ on the arousal subscale. By extrapolating this rule, we hypothesize that this case would have been either moderate or high risk of non-recovery at 
baseline, given her current NDI of $36 \%$ ad IES of $69 / 75$. Ritchie et al ${ }^{1}$ further state that the moderate risk patient will either recover or not, however high risk patient will not recover. Given that ultimately this case recovered, we hypothesize that she was more likely at moderate risk at baseline. We argue, that if she were at low risk, then recovery would have occurred prior to the 3 years when she presented for further treatment. Should we therefore, consider the medium risk category as the most likely to benefit from physiotherapy-led interventions and or referral to those with more specialist training? $\mathrm{A}$ risk based stratification approach tested in patients with $\mathrm{WAD}^{50}$ will ultimately answer this question.

Physiotherapists have been cautioned not to rely completely on evidence when it does not provide answers ${ }^{52}$. Rather to combine a clinical reasoning approach informed by the evidence. In presenting this case, it is hoped that physiotherapists will continue to look for answers for their patients, to identify responders and non-responders to their interventions, so that in time we are able to more consistently identify who will benefit from our care, and ultimately improve recovery for this group.

\section{Summary}

Each of these three cases bring a different amount of learning to the management of cervical spine patients. Case study 1 illustrates the need to consider all aspects of the patient's presentation including the general health when vascular issues are in play as well as presenting musculoskeletal features. Guidelines are useful in clinical practice to improve patient care based on best practice evidence. However these are often slow to implement in practice and individual case studies such as the one presented can be helpful to get key 
messages across. Case study two illustrates the need for well applied and specific manual therapy to target the main areas of dysfunction and the dramatic effect this may have on patient outcomes and the powerful impact of well applied MT. The final case demonstrates that all patients are different and at time evidence and guidelines do not guide the outcome as well as clear clinical reasoning and experience. Subgrouping of patients is clearly useful to get the best outcomes but also being aware of the fact that MT and exercise when possibly not indicated can have a positive effect when appropriately applied. Clinical reasoning is still at the cornerstone of good practice and is a skill all therapist should continue to foster and reflect on. 


\section{References}

1. Sackett, D., Rosenberg, W., Gray, J., et al . Evidence Based Medicine: What it is and what it isn't. BMJ, 1996. 312(7023), 71-72. http://doi.org/10.1136/bmj.312.7023.71

2. Schievink W, Mokri B, Whisnant J. Internal carotid artery dissection in a community. Rochester, Minnesota, 1987-1992. Stroke 1993;24:1678-80

3. Lee VH, Brown Jr. RD, Mandrekar JN, Mokri B. Incidence and outcome of cervical artery dissection. Neurology 2006;67:1809-12.

4. Haneline M, Lewkovich G. An analysis of the aetiology of cervical artery dissections: 1994 to 2003. J Manipulative Physiol Ther 2005;28:617-22

5. Rivett, D. A., \& Reid, D. Risk of stroke for cervical spine manipulation in New Zealand. NZ J Physiother, 1998 26, 14-17. Retrieved from http://nzsp.org.nz/index02/Publications/Journals.htm

6. Jaskoviak, P. A. Complications arising from manipulation of the cervical spine. J Manipulative Physiol Ther, 1980. 3(4), 213-219. Retrieved from http://www.jmptonline.org

7. Magarey, M. E., Rebbeck, T., Coughlan, B.,et al Pre-manipulative testing of the cervical spine review, revision and new clinical guidelines. Man Ther, 2004. 9(2), 95108. doi:10.1016/j.math.2003.12.002

8. Ritcher, R and Reinking,M. How does evidence on the diagnostic accuracy of the vertebral artery test influence teaching of the test in a professional physical therapist education program? Phys Ther . Volume 85 . Number 6. June 2005

9. Rushton, A., Rivett, D, Carlesso, L et al International framework for examination of the cervical region for potential of Cervical Arterial Dysfunction prior to Orthopaedic Man Ther intervention. Manual Therapy 2014 (19) 222-228 
10. Vaughan, B, Moran, R Tehan, et al. Manual therapy and cervical artery dysfunction: Identification of potential risk factors in clinical encounters. Int J Osteopathic Med (2016) $21,40-50$

11. Arnold M, Bousser G, Fahrni G, et al (2006). Vertebral Artery Dissection Presenting Findings and Predictors of Outcome. Stroke 37:2499-2503.

12. Fuller G (2008). Neurological examination made easy. 4th Edition, Elsevier.

13. Jull GA, O'Leary SP, Falla DL. Clinical assessment of the deep cervical flexor muscles: the craniocervical flexion test. J Manipulative Physiol Ther. Sep 2008;31(7):525-533.

14. Treleaven J, Jull G, LowChoy N. Smooth pursuit neck torsion test in whiplashassociated disorders: relationship to self-reports of neck pain and disability, dizziness and anxiety. J Rehabil Med. Jul 2005;37(4):219-223.

15. Ishii T, Mukai Y, Hosono N, et al. Kinematics of the Upper Cervical Spine in Rotation: In Vivo Three-Dimensional Analysis. Spine. 2004;29(7):E139-E144.

16. Ballenberger N, von Piekartz H, Paris-Alemany A, La Touche R, Angulo-Diaz-Parreno S. Influence of different upper cervical positions on electromyography activity of the masticatory muscles. J Manipulative Physiol Ther. May 2012;35(4):308-318.

17. Grondin F, Hall T, von Piekartz H. Does altered mandibular position and dental occlusion influence upper cervical movement: A cross-sectional study in asymptomatic people. Man Ther. Jun 152016.

18. McCarthy CJ. Spinal manipulative thrust technique using combined movement theory. Man Ther. Nov 2001;6(4):197-204.

19. Edwards BC. Manual of Combined Movements: Their Use in the Examination and Treatment of Mechanical Vertebral Column Disorders. Perth: Churchill Livingstone; 1999. 
20. Zusman M. Phys Ther Rev. 2004;9(null):39.

21. Mancini F, Beaumont AL, Hu L, Haggard P, lannetti GD. Touch inhibits subcortical and cortical nociceptive responses. Pain. Oct 2015;156(10):1936-1944.

22. Lluch E, Arguisuelas MD, Calvente Quesada O, et al. Immediate effects of active versus passive scapular correction on pain and pressure pain threshold in patients with chronic neck pain. J Manipulative Physiol Ther. Nov-Dec 2014;37(9):660-666

23. Mirtz TA, Morgan L, Wyatt LH, Greene L. An epidemiological examination of the subluxation construct using Hill's criteria of causation. Chiroprac \& Osteopathy. 2009;17(1):13.

24. Piovesan EJ, Kowacs PA, Oshinsky ML. Convergence of cervical and trigeminal sensory afferents. Current Pain and Headache Reports. 2003;7(5):377-383.

25. Spitzer W, Skovron M, Salmi L, Cassidy J, Duronceau J, Suissa S. Scientific monograph of Quebec task force on whiplash associated disorders: redefining 'whiplash' and its management. Spine. 1995;20(8S):1-73.

26. Michaleff Z, Maher C, Lin C, et al. Comprehensive phyisotherapy exercise programmee or advice for chronic whiplash (PROMISE): a pragmatic randomised controlled trial. . Lancet. 2014; in press.

27. Sterling M, Kenardy J, Sterling M, Kenardy J. Physical and psychological aspects of whiplash: Important considerations for primary care assessment. Man Ther. May 2008;13(2):93-102.

28. Sterling M, Hendrikz J, Kenardy J, et al. Assessment and validation of prognostic models for poor functional recovery 12 months after whiplash injury: a multicentre inception cohort study. Pain.153(8):1727-1734.

29. Sterling M, Carroll LJ, Kasch H, Kamper SJ, Stemper B. Prognosis after whiplash injury: 
where to from here? Discussion paper 4. Spine.36(25 Suppl):S330-334.

30. Jull G, Sterling M, Kenardy J, Beller E. Does the presence of sensory hypersensitivity influence outcomes of physical rehabilitation for chronic whiplash? - A preliminary RCT. Pain. 2007;129(2):28-34.

31. Stewart M, Maher C, Refshauge K, Herbert R, Bogduk N, Nicholas M. Randomised controlled trial of exercise for chronic whiplash associated disorders. Pain. 2007;128(1-2):59-68.

32. Sullivan MJL, Bishop SR, Pivik J. The Pain Catastrophizing Scale: Development and validation.Psychological Assessment. Psychological Assessment. 1995;7(524-532).

33. Ogince $M$, Hall $T$, Robinson $K$, Blackmore AM. The diagnostic validity of the cervical flexion-rotation test in C1/2-related cervicogenic headache. Man Ther.12(3):256262.

34. Hall TM, Briffa K, Hopper D, Robinson KW. The relationship between cervicogenic headache and impairment determined by the flexion-rotation test. J Manipulative Physiol Ther.33(9):666-671.

35. Kaur K, Das P, Lenka P, Anwer S. Immediate Effect of Posture Correction of Trapezius Activity in Computer Users Having Neck Pain-An Electromyographic Analysis. The Int J Allied Health Sciences and Prac. 2013;11(4)

36. Jull G, Sterling M, Falla D, Treleaven J, S OL. Whiplash, headache and neck pain. Research based directions for physical therapists. . Edinburgh: Elsevier; 2008.

37. Jull GA, O'Leary SP, Falla DL. Clinical Assessment of the Deep Cervical Flexor Muscles: The Craniocervical Flexion Test. J Manipulative Physiol Ther. 9// 2008;31(7):525-533. 38. Sterling M. A proposed new classification system for whiplash associated disordersimplications for assessment and management. Man Ther. 2004;9(2):60-70. 
39. Falla D, Bilenkij G, Jull G. Patients with chronic neck pain demonstrate altered patterns of muscle activation during performance of a functional upper limb task. Spine. 2004;29(13):1436-1440.

40. Zakharova-Luneva E, Jull G, Johnston V, O'Leary S. Altered Trapezius Muscle Behavior in Individuals With Neck Pain and Clinical Signs of Scapular Dysfunction. J Manipulative Physiol Ther. 2012;35(5):346-353.

41. Behrsin JF, Maguire KEN. Levator Scapulae Action during Shoulder Movement: A Possible Mechanism for Shoulder Pain of Cervical Origin. Aust J Physiother. 1986;32(2):101-106.

42. Lindstrøm R, Schomacher J, Farina D, Rechter L, Falla D. Association between neck muscle coactivation, pain, and strength in women with neck pain. Man Ther. $2011 ; 16(1): 80-86$.

43. Lluch E, Arguisuelas MD, Coloma PS, Palma F, Rey A, Falla D. Effects of Deep Cervical Flexor Training on Pressure Pain Thresholds Over Myofascial Trigger Points in Patients With Chronic Neck Pain. J Manipulative Physiol Ther. 2013;36(9):604-611.

44. Falla D, O'Leary S, Farina D, Jull G. The change in deep cervical flexor activity after training is associated with the degree of pain reduction in patients with chronic neck pain. Clin J Pain. 2012;28(7):628-634.

45. Clinical guidelines for best practice management of acute and chronic whiplashassociated disorders. National Health and Medical Research Council of Australia; 2008. Accessed December 2008.

46. Verhagen AP, Scholten-Peeters GGGM, van Wijngaarden S, de Bie R, Bierma-Zeinstra SMA. Conservative treatments for whiplash. Cochrane Database of Systematic Reviews. 2008;4. 
47. Cortet B. [Postmenopausal osteoporosis: general practitioners' application of the risk factors in the AFSSAPS guidelines. Survey of 2658 general practitioners ]. Presse Medicale.38(9):1213-1219.

48. Finestone AS, Raveh A, Mirovsky Y, Lahad A, Milgrom C. Orthopaedists' and family practitioners' knowledge of simple low back pain management. Spine.34(15):16001603.

49. Ritchie C, Hendrikz J, Kenardy J, Sterling M. Development and validation of a screening tool to identify both chronicity and recovery following whiplash injury. . Pain. 2014; under review.

50. Ritchie C, Hendrikz J, Kenardy J, Sterling M. Derivation of a clinical prediction rule to identify both chronic moderate/severe disability and full recovery following whiplash injury. Pain. 2013;154(10):2198-2206.

51. Rebbeck T, Leaver A, Bandong AN, et al. Implementation of a guideline-based clinical pathway of care to improve health outcomes following whiplash injury (Whiplash ImPaCT): protocol of a randomised, controlled trial. Journal of Physiotherapy. 4// 2016;62(2):111.

52. Crosbie J. Does a stubborn commitment to 'evidence' stifle innovative thinking? J Physiother.59(2):69-71. 
Table 3 : Quebec Task Force classification of grades of WAD

\begin{tabular}{|ll|}
\hline $\mathbf{0}$ & No complaint about the neck \\
& No physical signs \\
\hline $\mathbf{1}$ & Complaint of neck pain, stiffness or tenderness only \\
& No physical signs(s) \\
& Neck complaint AND musculoskeletal signs \\
II & tenderness \\
\hline III & Neck complaint AND neurological signs \\
& Neurological signs include decreased or absent tendon reflexes, weakness \\
& and sensory deficits \\
\hline IV & Neck complaint and fracture or dislocation \\
\hline
\end{tabular}

